\title{
PCE IN ANALYSIS MODELS OF THE NUMBER OF FOLLOWING VEHICLES ON A TWO-LANE ROAD
}

\author{
Marko Subotić ${ }^{1}$, Vladan Tubić ${ }^{2}$, Bojan Marić ${ }^{3}$ \\ ${ }^{1,3}$ University of East Sarajevo, Faculty of Transport and Traffic Engineering, Vojvode Mišića 52, 74000 \\ Doboj, Bosnia and Herzegovina \\ ${ }^{2}$ University of Belgrade, Faculty of Transport and Traffic Engineering, Vojvode Stepe 305, 11000 \\ Belgrade, Serbia
}

Received 15 December 2015; accepted 11 January 2016

\begin{abstract}
This paper analyzes the influence of heavy-duty vehicles (HDV) on the traffic capacity of a two-lane road depending on weather conditions. The influence of the heaviest vehicles moving is expressed by the passenger car equivalents - PCE. The research was performed in Bosnia and Herzegovina, on section M-17 of the highway that tangents (touches) the zone of the city of Doboj, where the values of PCE for heavy-duty vehicles were measured at three sections with interference of on ramps and off ramps. By determining the time headway, PCE factors and their influence on traffic capacity were analyzed. The research was done for three time headway variants PC-HDV, HDV-PC and HDV-HDV. Total measured PCE factors' value on the highway for all three sections and all three variants is 1.584; while comparing this value with HCM-2010 (Highway Capacity Manual) (TRB, 2010) it is between 1.4 and 1.5 (progressively decreasing with flow) which presents substantial deviation. That is why mathematical models for determining PCE of heavy-duty vehicles of two-lane road were developed in function of number of the following vehicles on dry and wet roadway. Developed model for establishing the PCE is based on determining time headway, which could be used to determine PCE values for particular number of following vehicles without interruption.
\end{abstract}

Keywords: PCE, heavy-duty vehicle, two-lane road, weather conditions, following vehicles.

\section{Introduction}

Many researches were conducted for understanding the effect of different categories of vehicles on traffic flow. PCE is used to estimate the effect of the influence of different categories of vehicles on traffic flow. Since the traffic flow is composed of various types of vehicles, PCE values are used for transferring the real traffic flow into the conditionaly homogenous flow. The beginnings of PCE date back in 1965 and many researchers have been trying to determine the quantity of effects of heavy vehicles in traffic flow using different methodologies and criteria of equality. According to the HCM-2000 (TRB, 2000), $P C E$ defines the number of passenger cars (PC) disposed to a single category of vehicle units, depending on the prevailing traffic conditions, i.e. the average number of passenger cars that would spend the same percentage of the road capacity like some other vehicle (HV, BUS, Car train) at given road and traffic conditions. Herewith a capacity measurement as a passenger car/

\footnotetext{
${ }^{2}$ Corresponding author: vladan@sf.bg.ac.rs
} 
hour $(\mathrm{PV} / \mathrm{h})$ is dimensioned. The presence of heavy-duty vehicles in the traffic flow in the vicinity of intersections (nodes) results also in decrease of capacity (Kockelman and Shabih, 1999). The impact of heavy-duty vehicles on the traffic flow is reflected in the fact that the heavy-duty vehicles are larger than passenger cars and so, they are taking up more space in a traffic flow. Also, heavy-duty vehicles have inferior technical-exploitation possibilities (acceleration and decelaration) than passenger cars, so they require longer distances between vehicles. Here, it is understood that drivers of other vehicles in the traffic flow keep longer distances compared to heavy vehicles (Ahmed, 2010).

\section{Historical Review and Influencing Factors}

For the first time, the PCE was incorporated into HCM in 1965 , so, the majority of past researches were conducted in the aim of determining the PCE for heavy-duty vehicles. Nevertheless, in 1950, there was used a single factor of two, needed for calculation of impact of heavy vehicles on multi-lane roads and highways on uniformed terrain (HRB, 1950). Many scientific papers, based on PCE study, were mainly related to assessment of PCE regarding the different categories of vehicles under different road and traffic conditions (Al Kaisy et al., 2005; Kimber et al., 1985; Sumner et al., 1984; Webster and Elefteriadou, 1999). There are different hronological approaches for establishing PCE. For example, HCM-2000 (HRB, $1965)$ is using the method of speed reduction for determining PCE for roads, known as Walker's method. For Huber (1982), there are three PCE performance measures: speed, density and speed of passenger car in both lanes. In 1980, Ramanayya (1980) used the name "equivalent of vehicle's design" instead of unit of passenger car for model of traffic observed on urban roads in India. The study of such a type is the first one measuring flows by metrics instead PCE values. It could be seen from the study that PCE values are not constant measurements due to heterogenous traffic conditions. This Indian model translates all vehicles into the unit of "equivalent of vehicle design”. Chari and Badrinath (1983) considered equivalents of heavy-duty vehicles through the density they named "areal density". It was the first study that considered area of the vehicle (as a surface that is covering) for measuring density. This density was defined as a vehicle projected on ground per unit of the road section. Determining the areal density was done by use of camera within one second time interval. Cunagin and Messer (1983) are using delays relations as a measure of performances for assessment of PCE of heavy-duty vehicles on multi-lane roads. Sumner et al. (1984) is using numer of vehicles per hour to express density equivalent since vehicle/h is the function of vehicle's speed and length. Madhava (1994) is using characteristics of traffic flow for studying traffic on National roads in India. By his study, the researchers were placed at the each branch of the intersection to collect data on time of entering, registration number and category of vehicle at that branch. Later on, for each minute of the interval, there was calculation of a number of vehicles at the branch of the intersection. Elefteriadou et al. (1997) is using average speed as a measure of performances, while the researches of Webster and Elefteriadou (1999) are based on determining density as a measure of performance for determining PCE. Singh (1999) is using concentration of vehicles as traffic characteristic for estimation of the model of simulation defined as a part of the road with the number of vehicle in a given moment. In his study, recording by video 
graphic on concentration of vehicles every 15 seconds was used. Nevertheless, Khan and Maini (1999) gave the wide overview of study of model of flow of heterogeneous traffic flow and concluded that for mixed category of vehicles, linear measuring of density is not adequate, so, the sections of moving vehicle should be measured. Also, in this study it was concluded that simple definition of PCE is not applicable and that the value of equivalents depends on: flow composition, saturation and location. Chandra and Sikdar (2000) are proposing method for PCE estimation for mixed traffic flow as the function of the vehicle's surface (length $\mathrm{X}$ width) and speed. The study done by AlKaisy et al. (2001) brought a conclusion that the effect of heavy-duty vehicles in traffic is much more evident in periods of congestions than in a less saturated conditions. This study streamed to demonstrate how the concept of limiting factors influences the impact of heavy-duty vehicles on the flow of traffic conditions. Al-Kaisy et al. (2002) is using a factor of discharge of line of vehicles as a performance measure for PCE estimation during the congestion of traffic flow. Bham and Benekohal (2004) are using the percent of the section occupied by the vehicle for better presentation of the conditions of traffic congestions when the traffic flow is composed of vehicles of various lengths. According to their researches, the section occupied by vehicles presents better insight into the traffic state because it involves the length of each vehicle in the calculation of density in relation to the length of the section. Chitturi and Benekohal (2008), Subotić et al. (2011) have estimated the impact of working zones on PCE and concluded that the values of equivalents are decreasing when there is increase of percentage of heavy-duty vehicles and also increase of traffic flow. Also, Ahmed (2010) had studied identifying of characteristics of heavy-duty vehicles that have the impact on the flow of vehicles on the roads in various conditions of congestion, with emphasis on the level of service. In his study, he is deriving PCE factors due to congestions or serious flow congestions and then he is comparing them with HCM-2000 (TRB, 2000).

\section{Research Hypothesis}

The goal of this research is based on hypothesis that the impact of heavy-duty vehicles on a two-line road in relation to passenger cars is bigger in saturated conditions of traffic flow then in less saturated conditions in the traffic flow. Also, to clarify the hypothesis, with increase of number of vehicles in line, there is increase of PCE. This hypothesis is related to heavy-duty vehicles and it is not applicable to medium and light trucks. Also, it is considered that the PCE value for heavyduty vehicles in real traffic flow is smaller in dry weather and better weather conditions then in rain and worse weather conditions.

It is important to clarify the fact that in hypothesis reviewing it should be started from the position to examine three variants of vehicle's moving, i.e. when PC follows HDV, when HDV follows PC and when HDV follows HDV.

The focus is on the events that are in all three variants based on the measurement of time headway, based on which the values of PCE are determined, but not in the circumstances and events within the following vehicles or traffic flow, as well as on developments within the following vehicles that are driven by the very nature of interference, volume of overload and similar. The focus of this research is on the events that occur in a 
real traffic flow, during the arrival of the following vehicles. Actually, this assumption is up to fact that there is a greater impact of heavy-duty vehicles on the traffic flow of two-lane road during the passing of a longer line of following vehicles through an intersection, then during the passing of a shorter line of following vehicles of the traffic flow (De Luca et al., 2012). If it is proven that this claim is to be true, it may explain the changes in the capacity of the section, upon the occurrence of congestion.

\section{Approach to the Research}

There are several approaches for determining the impact of heavy-duty vehicles on vehicle's movement in the traffic flow. Therefore, there is a basis for defining the order that could determine PCE values (Ahmed, 2010). The most common approaches for determining the PCE value are:

- Constant relation of flow and capacity approach - appropriate for calculation of PCE when the level of the service was considered for perception of PCE calculation. This approach is not applicable for determining PCE under the conditions of dynamic balance.

- Equal density approach is related to a difference between two traffic flows (only PC, mixed traffic), when flows function at equal density. Flows having different speed have also different levels of freedom of maneuver. Therefore, it is proposed that the basis for equaling of two flows must not be equal to a density, but to densities which relate on the same way to conditions of drivers behaving towards other vehicles as well as to their freedom of maneuver.
- Spacial/Emptiness approach (temporal time headway) is one of the most represented methods. This method was developed ever since 1947 by Greenshields and is known in literature as the base method for confirming time headways. The concept of this method is simple and based on Eq. (1):

$\mathrm{PCE}_{\mathrm{i}}=\frac{\mathrm{H}_{\mathrm{i}}}{\mathrm{H}_{\mathrm{PC}}}$

where the following mean:

$P C E_{i}$ - passenger car equivalent of an i-class vehicle;

$H_{i}$ - average value of the time headway of an i-class vehicle;

$H_{P C}$ - average value of the time headway for a passenger vehicle.

The spatial method of distance is considered as a replacement for the density measurement. Both of these methods have an influence on the freedom of maneuvering in traffic flow. Based on the research of Cunagin and Chang (1982), the distance for trucks that follow other trucks is significantly smaller than for a passenger car that is following a truck. Because of that, Krammes and Crowley (1986) suggest the PCE to be calculated as Eq. (2):

$\mathrm{E}_{\mathrm{T}}=\frac{\left(1-\mathrm{P}_{\mathrm{T}}\right) \cdot \mathrm{H}_{\mathrm{TP}}+\mathrm{p} \cdot \mathrm{H}_{\mathrm{TT}}}{\mathrm{H}_{\mathrm{P}}}$

where the following mean:

$P_{T}$ - share of trucks in percentage;

$H_{T P}$ - distance of a truck that is following a passenger car in mixed flow;

$H_{P T}$ - distance of a passenger car that is following a truck in mixed flow and $H_{P}$ - distance of a passenger car that is following any type of vehicle in mixed flow. 
For the needs of this paper, research was done in three sections, so, based upon a referential sample and in the shape of a reccomendation, we could define the values of equivalents adapted to a certain traffic condition.
Usage of the model for calculating PCE is tied to a Eq. (1). In the context of defining methodology and research technique, choice of location and data processing method, the following elements and criteria were used.

\section{Table 1}

Measurement Criteria of Time Headway

\begin{tabular}{|l|l|}
\hline Applied methodology & $\begin{array}{l}\text { The basic method of relative time headway relations, observation of two basic vehicle } \\
\text { categories (PC and HDV (where BUS also belongs)) }\end{array}$ \\
\hline Recording technique & Manual, via application of a special measuring device \\
\hline Choice of location & $\begin{array}{l}\text { Physical elements: standard two-lane road (main road), inexistent longitudinal gradient } \\
\text { approach }\end{array}$ \\
\cline { 2 - 3 } & $\begin{array}{l}\text { Traffic criteria: great traffic encumbrance, bigger share percentage of commercial vehicles } \\
(15 \text { or more), a straight traffic lane or a mixed lane with a very small turning percentage, } \\
\text { inexistent parking or bus stop influence, realization of recording in a peak and non-peak } \\
\text { period }\end{array}$ \\
\hline Data processing & $\begin{array}{l}\text { Based on average values of individual locations and the summary average value, the analysis } \\
\text { dismisses the influence of the vehicles's position in line }\end{array}$ \\
\hline
\end{tabular}

Still, before we begin to approach the analysis of the value of equivalents, that is, determining temporal time headways, we determined a structure of vehicles in flow in all three sections. The measure value which is expressed in percentage refers to $76.9 \%$ of passenger cars, which tells us about the realistic influence of commercial vehicles of 23.1\%. Respectively, studying PCE values for a two line road can be justified, because the influence of commercial vehicles, especially HDV, on traffic flow is great.

This method is known under the name "distance method" (Kockelman and Shabih, 1999). Practically, applied procedures are used for many types of vehicles that fall into the heavy-duty vehicles category. This method of determining PCE equivalents is also used in the scope of this research, based upon which the representative values of PCE equivalents were gained.

\section{Limits and Choice of Research Location}

Several important conditions for the choice of analysed locations should be pointed out. These conditions refer to the limits in doing the research. They are reflected in the following:

- Heavy-duty vehicles in a realistic traffic flow consist of trucks with a trailer, autotrains and BUS, due to the adaptation to HCM-2010 methodology (TRB, 2010). This research did not take into account public transport, specialized vehicles, firefighters' vehicles and vehicles with other uses;

- The composition of the traffic flow on the observed location is heterogeneous and contains enough heavy-duty vehicles in the percentage share, with noticeable variations in traffic (passenger car compared to an HDV); 
- The influence of pedestrians on realistic traffic flow was not considered, because the measurement was not done in pedestrian crossing zones, nor in places where pedestrians gravitate to in the road zone;

- On the given measurement section only a single signaled four way crossing exists (near section 2), whose direct influence on recording is negligible, therefore it was not considered in this study;

- A visible location for a camera was determined, which enabled a precise measuring of temporal sequential distance, based on footage recorded in May and June 2011.

The given location of the road section is in Doboj, Bosnia and Herzegovina, and is suitable for measuring temporal time headways, therefore also suitable for determining PCE values. This location can be taken into account as representative from the aspect of gaining adequate data. This research covers the section with several access points which often service saturated traffic flows.

\subsection{Description of the Location}

This location is known for temporary clogs in morning and afternoon hours due to increase of transit flow frequency, commutes, deliveries etc. The road section was monitored for sections which had been negligibly influenced by the inflow and outflow of vehicles from the city zone. The length of the observed road section is approximately 3700 meters, with one signaled crossing. Traffic on a road section which increases in the peak hours is mostly comprised of drivers who tend to drive every day. The traffic was recorded with a camera from the sidelines. By positioning the camera, its influence on holding up passenger cars as well as heavy-duty vehicles, was eliminated and the goal of its placement is measuring the temporal time headway by using video recording.

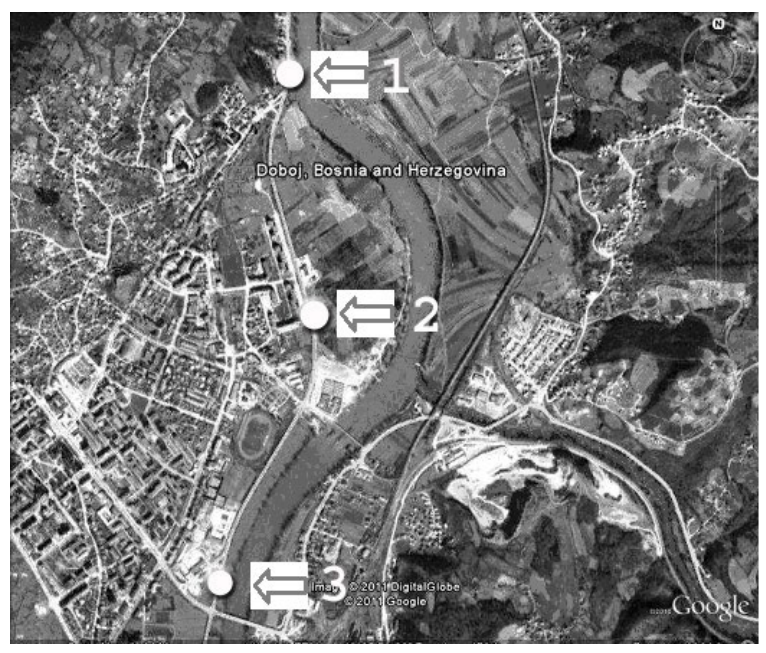

Fig. 1.

Measuring Locations of the Temporal Time Headway on Cross Sections of M-17 
The representativeness of the road corridor is reflected by the fact that the sections taken on the heavy encumbrance road. Therefore the PCE values for all sections of this road corridor can be hypothetically accepted as representative values.

\section{Analysis of Research Results}

According to the goal and program of the conducted research, it is necessary to determine the correlation between the number of following vehicles in line and the PCE. With the acquired results, this dependence can be shown in an analytical and graphical shape of a mathematical model for dry and wet weather.

The plan and program of the conducted research had predicted measuring for different following vehicle lengths. As the standard PCE value in this research for the PC-PC sequence, a hypothetical value of the equivalent 1 was adopted. Since the measured value of the traffic flow was within the 268-316 vehicles/hour/lane range, it was visually confirmed that the number of measured time headway that meet in line was given as $n-1$. Because the first vehicle was not taken into consideration, the maximum number of vehicles that were measured in a line was limited to 15 , which gave us 14 measuring results for the PCE, and did not

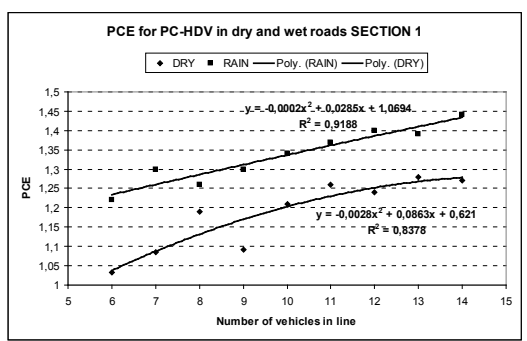

Fig. 2.

PCE for PC-HDV, Section 1 go below 7 vehicles during the measuring, which resulted in 6 gained measurement values of PCE. The given results had given a determined correlation of the number of vehicles in line that are coming into a line and the PCE values in dry and rainy weathers, so the curve that represents that correlation is approximated by a polynomial of the appropriate degree. Because of the preference for practical application of the form, we have given up on forming polynomials with a degree higher than 2 , so the approximation will be done with a second degree polynomial which ensures a sufficient accuracy of the approximation.

The dependency of the number of vehicles in line and PCE values in rain and dry land is presented by the following binomial:

$\mathrm{Y}=\mathrm{A} \cdot \mathrm{x}^{2}+\mathrm{B} \cdot \mathrm{x}+\mathrm{C}$

where:

$Y$ - measured value of PCE;

$x$ - number of vehicles in a line;

A, B, C - coefficients.

Data which was gained via experimental research was processed for all measuring places and sorted into classes by number of vehicles in a line, depending on the combination of following vehicle after vehicle, and was modeled on pictures 2-10.

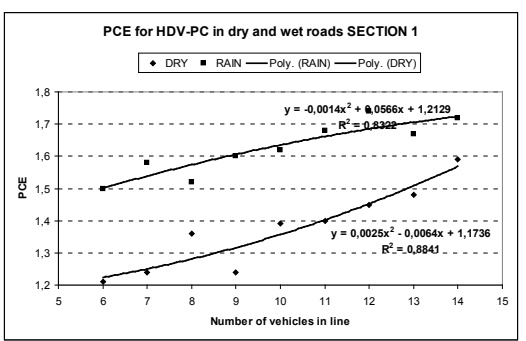

Fig. 3.

PCE for HDV-PC, Section 1 


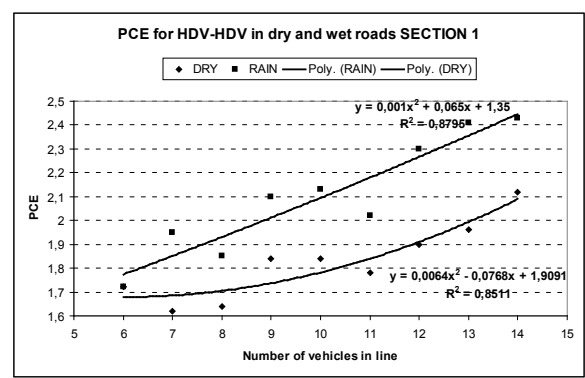

Fig. 4.

PCE for HDV-HDV, Section 1

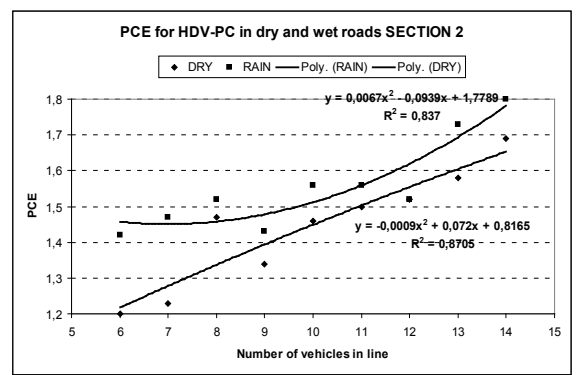

Fig. 6.

PCE for HDV-PC, Section 2

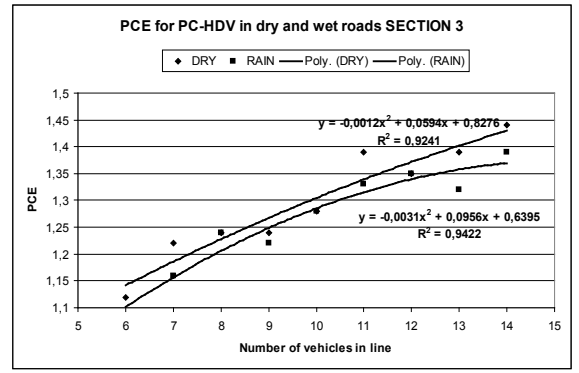

Fig. 8.

PCE for PC-HDV, Section 3

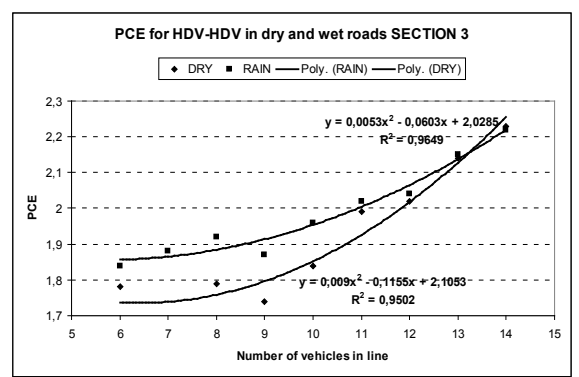

Fig. 10.

PCE for HDV-HDV, Section 3

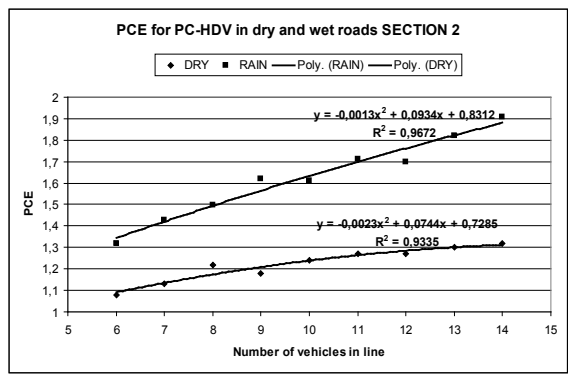

Fig. 5.

PCE for PC-HDV, Section 2

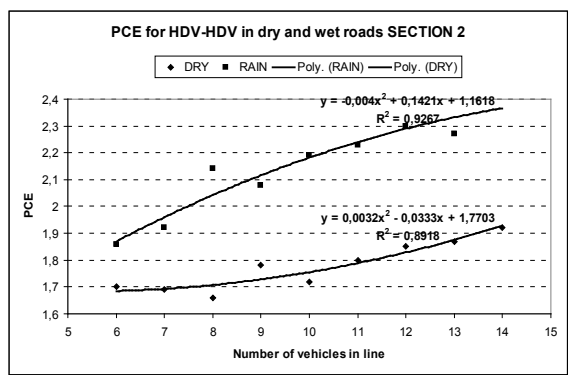

Fig. 7.

PCE for HDV-HDV, Section 2

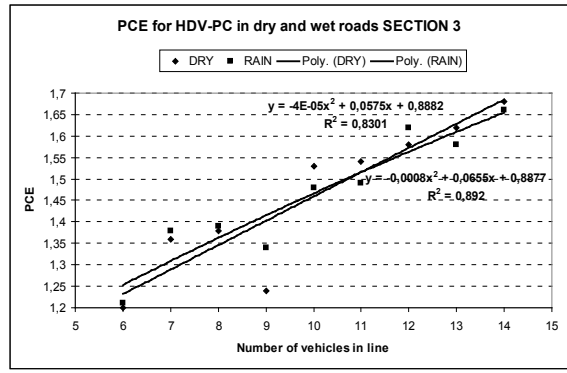

Fig. 9.

PCE for HDV-PC, Section 3 
Only HDV and BUS, which belong to the same vehicle category were monitored thereby analyzing their interaction with PC. The gained second degree polynomial equations which are given in the diagrams which show the number of vehicles in a line (which is in the 6-14 vehicle range) can be used as a reliable form during the capacity analysis and permeable power of the road, because the measurement results, based upon which the confirmed dependence was gained via measuring in an objective way.

By determining PCE values on sections, a total equivalent was gained, which equals 1.54 for section $1,1.605$ for section 2 , and 1.608 for section 3 . These values were determined as the arithmetic mean of all measured values (without regard to rainy and dry weather). The maximum determined average value of PCE in observed sections of the two line road is 2.637 .

It is an average value that was determined during the measurements of an HDV that was following an HDV in rainy weather, which tells us that weather conditions have a great deal of influence on vehicle movements and their mutual interaction. The minimum measured average value for PCE was 1.036 when a PC follows a HDV. Keep in mind that the speed limit in these conditions is $50 \mathrm{~km} / \mathrm{h}$ (De Luca et al., 2012).

With a rough analysis of the research data gained in the diagrams 2-10, we can see a significant deviation of PCE values for different pairs of vehicles (PC-HDV, HDV-PC and HDV-HDV) depending on the number of vehicles in line, and different weather conditions.

The influence of bad weather significantly disrupts the drivers' orientation and creates psychological influence, which creates greater distances between vehicles. Since the analysis covered three sections, it was determined that the smallest deviation of PCE values was in section 3 , which can be justified with a greater distance from any sort of intercrossing in that level.

In section 3, the PCE values in dry and wet roads are almost equal for all pairs of vehicles which participated in the observation. Still, the biggest deviation in PCE values is in section 1 , because that zone has an intercrossing in that level in the immediate vicinity, which significantly affects the deviations of PCE values in different weather conditions. In principle, the biggest deviations in PCE values in dry and wet roads was in section 2 (PC-HDV) and section 1 (HDV-PC), while in section 3 (HDV-PC) the PCE values were almost equal in dry and wet conditions, regardless of the number of vehicles in line.

The gained correlation coefficient values are acceptable, seeing that value $\mathrm{R}^{2}$ is not under 0.85 anywhere. A high degree of correlation such as this is explained by molding the vehicle classes according to average values measured for a sample. 


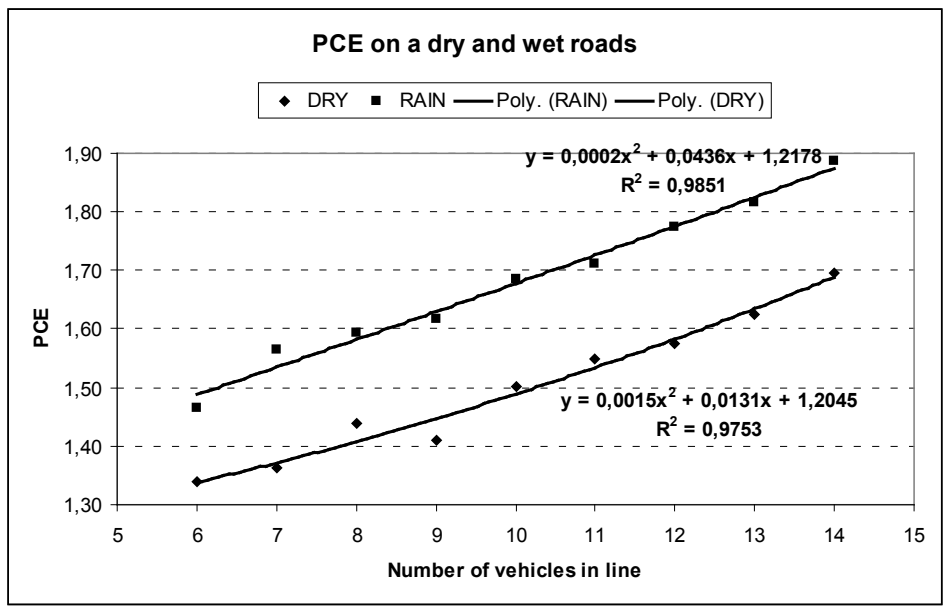

Fig. 11.

Determining PCE in Dry and Rainy Weather on a Two-Lane Road

Based on the analytical expression of the dependence of number of vehicles in line and the PCE on the Fig. 11 a diagram which makes it simple to determine the PCE values depending on the number of vehicles in a line line (and vice-versa) in dry and wet roads is shown. It is evident that the PCE value for the realistic usual line length was in the 1.30 (for at least 6 vehicles in line)-1.90 (for 14 vehicles in line) range. For lines with a smaller number of vehicles from the modeled number of vehicles in line, they were not taken into consideration because they do not give a realistic PCE value (Shih-Ching, 2012).

Still, by considering the weather conditions it was determined that rain has a significant influence on the PCE equivalents (Mashros et al., 2012). The influence of rain raised the PCE values by an average of 0.2 , which is a significant deviation. As a proof, we present the determined average PCE value in rain for all sections, which is 1.663 , and the determined average PCE value in dry weather is 1.553 . The amount of difference in the deviation between PCE in rain and PCE in dry weather for all sections and vehicle combinations is 0.11 , which can be considered justified because the weather conditions significantly reduce the vehicles mobility, speed, acceleration, as well as increase the distance between following vehicles etc. The equivalent indicator for dry weather does not deviate much from the HCM-2010 (TRB, 2010) which, in these circumstances, according to the measured flow is between 1.4 and 1.5 (with flow increase, it increases on a two-lane road for two way traffic), but the difference in PCE value deviation in rainy weather is evident. Also, with the analysis of pictures 2-10, it was determined that the smallest deviation in PCE values in different weather conditions was expressed in sections 3 for all 3 pairs of vehicles (PC-HDV, HDV-PC and HDV$\mathrm{HDV}$ ). In section 3 (HDV-PC), there was a concurrence of $\mathrm{PCE}$ values in circumstances 
when there were 10-12 vehicles in line, and 14 vehicles when the HDV-HDV variant was being observed. The global reduction in difference between PCE values for dry and wet weather in section 3 was shown in accordance with the increase of the number of vehicles in line.

\section{Discussion and Conclusions}

As the basic goal of this paper, mathematical models (graphical and analytical) were formed, which show the correlation between the PCE factor and the number of vehicles in a line. Within the scope of these models, it was concluded that the value of the equivalents depending on the length of the line of vehicles was between 1.30 and 1.90 , which is consistent with HCM-2010 (TRB, 2010), whose PCE value for road conditions on which all three sections are located varies between 1.4 and 1.5 and is dependent on the directional vehicle flow. Aside from that, PCE values in worse weather conditions grow progressively in all cases because of the reduction in technically - exploitative properties of the vehicles that are represented in the vehicle fleet on the two-lane magistral road. The basic conclusion of this research is that the progressive growth of PCE values is consistent with the increase of the number of vehicles in line, which confirms the hypothetical conjectures. That is, the maximum PCE values were gained for a larger number of vehicles in a line, while the smaller values were gained for a lesser number of vehicles. Next, there was a desire to compare PCE values gained in different weather conditions (dry and wet) and data gained from HCM-2000 (TRB, 2000) and HCM-2010 manuals (TRB, 2010). Within the scope of the next chapter a few calibrated equations are given, which are applicable in realistic circumstances for gaining necessary data for traffic flow predictions. Determining the mathematical dependence between PCE and the number of vehicles in a line, is a reminder for data analysis focused on the identification of additional factors which affect heavy-duty vehicles and passenger cars, as well as their interaction, and especially factors which can have an influence on distances and other parameters of these two vehicle categories (Shih-Ching, 2012). Also, the claim of many aforementioned researches is evident, and states that PC drivers maintain longer distances when they follow heavy vehicle, than when they follow a passenger car. The heavy-duty vehicles have a significant influence on movement conditions of vehicles in line, where the average PCE value is 1.584 , which is more than the HCM-2000 (TRB, 2000) value (1.10 in two-way traffic conditions) and approximate to the HCM-2010 (TRB, 2010) value (between 1.4 and 1.50). The big defect is that both versions of HCM observe PCE value determining only through traffic flows, and not through weather conditions as well as traffic flows. The reccomendations for future research refer to the possibility of tracking PCE equivalents in multiple road corridors, which would have the goal of forming models for running traffic based on PCE and the estimation of permeability of observed roads. Also, it would be desirable that future data collection locations include the possibility of systematic vehicle classification, vehicle selection by mass and axial stress. It would also be prudent to assume that heavy-duty vehicle drivers base their choice on keeping distance according to vehicle mass. Aside from that, by using Eq. (2) it is possible to analyze values of a saturated flow, which serves to percieve the permeability of traffic lanes. 


\section{References}

Ahmed, U. 2010. Passenger Car Equivalent Factors for Level Freeway Segments Operating under Moderate and Congested Conditions, Master's Theses (2009 - ) Marquette University. Milwaukee, Wisconsin, paper 60.

Al Kaisy, A.; Jung, Y.; Rakha, H. 2005. Developing Passenger Car Equivalency Factors for Heavy Vehicles during Congestion, Journal of Transportation Engineering, 131(7): 514-523.

Al-Kaisy, A.; Hall, F.; Reisman, E. 2002. Developing Passenger Car Equivalents for Heavy Vehicles on Freeways During Queue Discharge Flow, Transportation Research: Part A, 36(8): 725-742.

Al-Kaisy, A.; Hall, F.; Reisman, E. 2001. Developing passenger car equivalents for heavy vehicles on congested freeways: A capacity based approach. Presented at the 80th Annual Meeting of the Transportation Research Board, Washington, D.C.

Bham, G.H.; Benekohal, R.F. 2004. A High Fidelity Traffic Simulation Model based on Cellular Automata and Car-Following concepts, Transportation Research: Part C, Emerging Technologies, 12(1): 1-32.

Chandra, S.; Sikdar, P.K. 2000. Factors affecting PCU in mixed traffic situations on urban roads, Road and Transport Research, 9(3): 40-50.

Chari, S.R.; Badrinath, K.M. 1983. Study of mixed traffic stream parameters through time lapse photography, Highway Research Bulletin (Indian Road Congress, Highway Research Board), No 20, 57-65.

Chitturi, M.V.; Benekohal, R.F. 2008. Passenger car equivalents for heavy vehicles in Work Zones. Presented at the 87th Annual TRB Meeting of the Transportation Research Board, Washington, D.C.
Cunagin, W.; Chang, C. 1982. Effects of Trucks on Freeway Vehicle Headways under Off-Peak Flow Conditions. In Transportation Research Record: Journal of the Transportation Research Board, TRB, National Research Council, Washington, D.C; No 869, 54-59.

Cunagin, W.D.; Messer, C.J. 1983. Passenger Car Equivalents for Rural Highways. In Transportation Research Record: Journal of the Transportation Research Board, TRB, National Research Council, Washington, D.C; No 905, 61-68.

De Luca, M.; Lamberti, R.; Dell'Acqua, G. 2012. Freeway Free Flow Speed: a case study in Italy. Presented at the 15 th meeting of the Euro Working Group on Transportation (EWGT) 2012, International scientific conference, Paris: Procedia - Social and Behavioral Sciences 00 (2012) 000-000.

Elefteriadou, L.; Torbic, D.; Webster, N. 1997. Development of passenger car equivalents for freeways, two-lane highways and arterials. In Tranportation Research Record: Journal of Transportation Research Board, TRB, National Research Council, Washington, D.C; No 1572, 51-58.

Highway Research Board (HRB). 1950. Highway Capacity Manual, Aplications Guide, Washington, D.C.

Highway Research Board (HRB). 1965. Highway Capacity Manual, Special Rep. No. 87, Dept. of Traffic and Operations, National Research Council, Committee on Highway Capacity, Washington, D.C.

Huber, M.J. 1982. Estimation of Passenger - Car Equivalents of Trucks in Traffic Stream. In Transportation Research Record: Journal of Transportation Research Board, TRB, National Research Council, Washington, D.C; No 869, 60-68.

Khan, S.; Maini, P. 1999. Modeling Heterogeneous Traffic Flow. In Transportation Research Record: Journal of the Transportation Research Board, TRB, National Research Council, Washington, D.C; No 1678, 234-241. 
Kimber, R.M.; McDonald, M.; Hounsell, N. 1985. Passenger car units in saturation flows: Concept, definition, derivation, Transportation Research Part B: Methodological, 19(1): 39-61.

Kockelman, K.; Shabih, R. 1999. Efect of vehicle type on the capacity of signalized intersections: The Case of LightDuty Trucks, The University of Texas at Austin, Austin, Texas, USA, 3-24.

Krammes, R.; Crowley, K.W. 1986. Passenger Car Equivalents for Trucks on Level Freeway Segments, In Transportation Research Record: Journal of Transportation Research Board, TRB, National Research Council, Washington, D.C; No 1091, 10-17.

Madhava, V.K. 1994. A Study of some traffic characteristics and simulation modeling of traffic operations on two lane highways, Ph. D Thesis, Indian Institute of Technology, Kharagpur, India.

Mashros, N.; Ben-Edigbe, J.; Rahman, R. 2012. Extent of Highway Travel Time Differentials Resulting from Rainfall Intensities, British Journal of Applied Science \& Technology, 2(3): 254-265.

Ramanayya, T.V. 1980. Simulation Studies on Traffic Capacity of Road Systems for Indian Conditions, Ph. D Thesis, National Institute of Technology, Warangal, India.

Rongviriyapanich, T.; Suppattrakul, C. 2005. Effects of motorcycles on traffic operations on arterial streets, Journal of Eastern Asia Society for Transportation Studies, 6: $137-146$
Shih-Ching, Lo. 2012. Equivalent Transformation for Heterogeneous Traffic Cellular Automata, International Journal of Mechanical and Industrial Engineering, 6: 63-67.

Singh, B. 1999. Simulation and Animation of Heterogeneous Traffic on Urban Roads, Ph. D Thesis, Indian Institute of Technology, Kanpur, India.

Subotić, M.; Tubić, V.; Anđelković, D. 2011. Research of the light duty vehicles equivalents at the mixed lanes of the signal crossroads at the central city zone, Mechanics Transport Communications, 0534(3): V1-V7.

Sumner, R.; Hill, D.; Shapiro, S. 1984. Segment passenger car equivalent values for cost allocation on urban arterial roads, Transportation Research Part A: General, 18(5-6): 399-406.

Transportation Research Board (TRB). 2010. Highway Capacity Manual, Volume 4. Aplications Guide, Washington, D.C.

Transportation Research Board (TRB). 2000. Highway Capacity Manual, 4th Ed., National Research Council, Washington, D.C.

Webster, N.; Elefteriadou, L. 1999. A simulation study of truck passenger car equivalents (PCE) on basic freeway sections, Transportation Research Part B: Methodological, 33(5): 323-336. 